\title{
Evaluating Water Reuse Applications under Uncertainty: A Novel Picture Fuzzy Multi Criteria Decision Making Medthod
}

\author{
Nguyen Xuan Thao \\ Faculty of Information Technology, Vietnam National University of Agriculture \\ Email: nxthao@vnua.edu.vn
}

Received: 03 July 2018; Accepted: 14 September 2018; Published: 08 November 2018

\begin{abstract}
Evaluation of water reuse options is also one of the applications of multi-criteria decision-making (MCDM) problems. In this paper, we refer to a new method for selecting the best water reuse option in the available options by using picture fuzzy MCDM.
\end{abstract}

Index Terms-Multi-criteria decision-making, picture fuzzy, dissimilarity measure, water reuse.

\section{INTRODUCTION}

Reuse of water refers to the treatment and rehabilitation of non-traditional or deteriorated water for beneficial purposes [10]. Water reuse is synonymous with using reclaimed water, which can provide an option to reduce water scarcity, especially under the new reality of climate change and the increase in human activities. Water reuse has become widespread all over the world to solve the depletion of water resources, leading to the reduced water supply. Evaluation of water reuse applications is a weight replacement process and the most appropriate selection of water reuse applications. From this, the assessment involves analyzing many criteria with social, technical, economic, political, environmental and technical aspects to ensure sustainable decision making [21]. The challenge with water reuse application evaluation (WRAE) is that alternatives are diverse in nature, and often have conflicting criteria. The fuzzy set theory [20] is a very effective method for solving such contradictory and uncertain problems.

Fuzzy set theory was introduced in 1965 by L. A. Zadeh. Immediately, it became a useful method to study the problems of imprecision and uncertainty. Since then, a lot of new theories treating imprecision and uncertainty have been introduced. For instance, intuitionistic fuzzy set was introduced in 1986, which is a generalization of the notion of a fuzzy set. While fuzzy set gives the degree of membership of an element in a given set, intuitionistic fuzzy set gives a degree of membership and a degree of non-membership. Picture fuzzy set [4] is an extension of the crisp set, fuzzy set and intuitionistic set. A picture fuzzy set has three memberships: a degree of positive membership, a degree of negative membership, and a degree of neutral membership of an element in this set. This approach is widely used by researchers in both theory and application. Dinh et al. investigate the distance and dissimilarity measure on picture fuzzy set and apply it in pattern recognition [13]. Hoa and Thong (2017) improved fuzzy clustering algorithms using picture fuzzy sets and applications for geographic data clustering [11]. Son $[7,8]$ given an application of picture fuzzy set in the problems of clustering. Dinh et al. introduced the picture fuzzy database and some examples on picture fuzzy database [12].

We often use decision-making methods because of the uncertainty and complexity of the nature of decisionmaking. By the MCDM methods, we can determine the best alternative from multiple alternatives with respect to some criteria. In recent times, the choice of suppliers has increasingly played an important role in both academia and industry. Therefore, there are many MCDM techniques developed for the supplier selection supplier selection [2, 3, 5, 9, 19, 22]. However, the above methods are limited to use in set theory. Therefore, it is difficult to encounter problems of uncertain or incomplete data. There are some authors who have proposed MCDM methods using fuzzy set theory or intuitionistic fuzzy set for the supplier selection $[4,6,9,14,16,17,18,21]$.

With the considered criteria for water reuse options, there are usually three levels. For example, the public acceptability attribute has three levels: agreement, disagreement, and neutrality; freshwater saving has also three levels: low, middle, and high. Therefore, we use the multi criteria decision making method based on picture fuzzy set to select the best alternative in evaluating water reuse applications. The rest of paper is organized as follows: section 2, we recall the concept of picture fuzzy set and some operators of two picture fuzzy sets. In section 3, we propose a new MCDM method using the similarity measure of picture fuzzy sets. Finally, we apply the proposed method for evaluating water reuse application in section 4 . 


\section{PRELIMINARITY}

In this section, we recall the definition of picture fuzzy sets and dissimilarity measure of them. After that, we introduce a new dissimilarity measure of picture fuzzy sets.

\section{A. Picture fuzzy sets}

Here we recall the concept of picture fuzzy sets.

Definition 1 [4]. Let $U$ be a universal set. A Picture fuzzy set (PFS) $A$ on the $U$ is $A=\left\{\left(u, \mu_{A}(u), \eta_{A}(u), \gamma_{A}(u)\right) \mid u \in U\right\}$ where $\mu_{A}(u)$ is called the "degree of positive membership of $u$ in $A ", \eta_{A}(u)$ is called the "degree of neutral membership of $u$ in $A$ " and $\gamma_{A}(u)$ is called the "degree of negative membership of $u$ in $A$ " where $\mu_{A}(u), \eta_{A}(u), \gamma_{A}(u) \in[0,1] \quad$ satisfy the following condition:

$$
0 \leq \mu_{A}(u)+\eta_{A}(u)+\gamma_{A}(u) \leq 1, u \in U
$$

The family of all picture fuzzy set in $U$ is denoted by $\operatorname{PFS}(U)$.

Definition 2. The picture fuzzy set $B=\left\{\left(u, \mu_{B}(u), \eta_{B}(u), \gamma_{B}(u)\right) \mid u \in U\right\}$ is called the subset of the picture fuzzy set $A=\left\{\left(u, \mu_{A}(u), \eta_{A}(u), \gamma_{A}(u)\right) \mid u \in U\right\} \quad$ iff $\mu_{B}(u) \leq \mu_{A}(u) \quad \eta_{B}(u) \leq \eta_{A}(u)$ and $\gamma_{B}(u) \geq \gamma_{A}(u)$ for all $u \in U$.

\section{B. Dissimilarity measure of picture fuzzy sets}

In this section, we recall concept of dissimilarity measure for picture fuzzy sets.

Definition 3. Given $U=\left\{u_{1}, u_{2}, \ldots, u_{n}\right\}$ is an universe set. For any $A, B \in P F S(U)$. A function Dis : $\operatorname{PFS}(U) \times P F S(U) \rightarrow[0,1]$ is a dissimilarity measure between PFS-sets if it satisfies follow properties:

PF-Diss 1: $\operatorname{Dis}(A, B)=\operatorname{Dis}(B, A)$;

PF-Diss 2: $\operatorname{Dis}(A, A)=0$

PF-Diss 3: If $A \subset B \subset C$ then

$\operatorname{Dis}(A, C) \geq \max \{\operatorname{Dis}(A, B), \operatorname{Dis}(B, C)\}$.

Now, we can identify some new dissimilarity measures between picture fuzzy sets.

Given $U=\left\{u_{1}, u_{2}, \ldots, u_{n}\right\}$ is an universe set. For any $A, B \in P F S(U)$, we denote

$$
T_{A}\left(u_{i}\right)=\mu_{A}\left(u_{i}\right)+\eta_{A}\left(u_{i}\right)-\gamma_{A}\left(u_{i}\right)
$$

$$
\begin{gathered}
T_{B}\left(u_{i}\right)=\mu_{B}\left(u_{i}\right)+\eta_{B}\left(u_{i}\right)-\gamma_{B}\left(u_{i}\right) \\
S_{A}\left(u_{i}\right)=\eta_{A}\left(u_{i}\right)-\gamma_{A}\left(u_{i}\right) \\
S_{B}\left(u_{i}\right)=\eta_{B}\left(u_{i}\right)-\gamma_{B}\left(u_{i}\right)
\end{gathered}
$$

and

$$
D_{i}(A, B)=\frac{\left|T_{A}\left(u_{i}\right)-T_{A}\left(u_{i}\right)\right|+\left|S_{A}\left(u_{i}\right)-S_{A}\left(u_{i}\right)\right|}{4}
$$

for all $i=1,2, \ldots, n$.

Definition 4. Given $U=\left\{u_{1}, u_{2}, \ldots, u_{n}\right\}$ is a universal set. For any $A, B \in P F S(U)$, a dissimilarity measure Dis : PFS $(U) \times P F S(U) \rightarrow[0,1]$ is defined by

$$
D M_{T}(A, B)=\frac{1}{n} \sum_{i=1}^{n} D_{i}(A, B)
$$

Theorem 1. $D M_{T}(A, B)$ in the eq.(6) is a dissimilarity measure on $\operatorname{PFS}(U)$.

Proof.

From eq.(1), eq.(2), eq.(3) and eq.(4), we have

$$
-1 \leq T_{A}\left(u_{i}\right), T_{B}\left(u_{i}\right), S_{A}\left(u_{i}\right), S_{B}\left(u_{i}\right) \leq 1
$$

for all $i=1,2, \ldots, n$.

Hence, according to Eq.(5) we have $D_{i}(A, B) \in[0,1]$.

So that, from Eq.(6) we have $D M_{T}(A, B) \in[0,1]$ for all $A, B \in P F S(U)$

(PF-Diss 1). It is obviously.

(PF-Diss 2). It is obviously.

(PF-Diss 3). If $A \subset B \subset C$ then

$$
\left\{\begin{array}{l}
\mu_{A}\left(u_{i}\right) \leq \mu_{B}\left(u_{i}\right) \leq \mu_{C}\left(u_{i}\right) \\
\eta_{A}\left(u_{i}\right) \leq \eta_{B}\left(u_{i}\right) \leq \eta_{C}\left(u_{i}\right) \\
\gamma_{A}\left(u_{i}\right) \geq \gamma_{B}\left(u_{i}\right) \geq \gamma_{C}\left(u_{i}\right)
\end{array}\right.
$$

for all $u_{i} \in U$.

So that $T_{A}\left(u_{i}\right) \leq T_{B}\left(u_{i}\right) \leq T_{C}\left(u_{i}\right)$

and

$$
S_{A}\left(u_{i}\right) \leq S_{B}\left(u_{i}\right) \leq S_{C}\left(u_{i}\right)
$$

Hence

$\left|T_{A}\left(u_{i}\right)-T_{C}\left(u_{i}\right)\right| \geq \max \left\{\left|T_{A}\left(u_{i}\right)-T_{B}\left(u_{i}\right)\right|,\left|T_{B}\left(u_{i}\right)-T_{C}\left(u_{i}\right)\right|\right\}$ and $\left|S_{A}\left(u_{i}\right)-S_{C}\left(u_{i}\right)\right| \geq \max \left\{\left|S_{A}\left(u_{i}\right)-S_{B}\left(u_{i}\right)\right|,\left|S_{B}\left(u_{i}\right)-S_{C}\left(u_{i}\right)\right|\right\}$ Hence $D M_{T}(A, C) \geq \max \left\{D M_{T}(A, B), D M_{T}(B, C)\right\}$. It means PF-Diss 3 satisfy. $\square$ 
Now, we assign $u_{i}$ is the weight $\omega_{i}$, such that $\sum_{i=1}^{n} \omega_{i}=1$. We can define a dissimilarity measure of two picture fuzzy sets as follows:

Definition 5. Given $U=\left\{u_{1}, u_{2}, \ldots, u_{n}\right\}$ is a universal set. For any $A, B \in P F S(U)$, a dissimilarity measure Dis: $P F S(U) \times P F S(U) \rightarrow[0,1]$ is defined by

$$
D M_{T}^{\omega}(A, B)=\sum_{i=1}^{n} \omega_{i} D_{i}(A, B)
$$

Definition 6. Given $U=\left\{u_{1}, u_{2}, \ldots, u_{n}\right\}$ is a universal set. For any $A, B \in P F S(U)$, a dissimilarity measure Dis: $\operatorname{PFS}(U) \times \operatorname{PFS}(U) \rightarrow[0,1]$ is defined by

$$
D M_{P}^{\omega}(A, B)=\sum_{i=1}^{n} \omega_{i} D_{i}^{P}(A, B)
$$

Where

$$
D_{i}^{P}(A, B)=\frac{\left|T_{A}\left(u_{i}\right)-T_{A}\left(u_{i}\right)\right|^{P}+\left|S_{A}\left(u_{i}\right)-S_{A}\left(u_{i}\right)\right|^{P}}{4}
$$

for all $i=1,2, \ldots, n, p \in N^{*}$

Theorem 2 Given $U=\left\{u_{1}, u_{2}, \ldots, u_{n}\right\}$ is a universal set. For any $A, B \in P F S(U)$. We have

$$
\begin{aligned}
& \text { a) } D M_{T}^{\omega}(A, B)=\frac{1}{n} \sum_{i=1}^{n} \omega_{i} D_{i}(A, B) \\
& \text { b) } D M_{P}^{\omega}(A, B)=\frac{1}{n} \sum_{i=1}^{n} \omega_{i} D_{i}^{P}(A, B)
\end{aligned}
$$

are the dissimilarity measure between picture fuzzy sets.

Proof.

a) We have

From eq.(1), eq.(2), eq.(3) and eq.(4), we have

$$
-1 \leq T_{A}\left(u_{i}\right), T_{B}\left(u_{i}\right), S_{A}\left(u_{i}\right), S_{B}\left(u_{i}\right) \leq 1
$$

for all $i=1,2, \ldots, n$.

Hence, according to Eq.(5) we have $D_{i}(A, B) \in[0,1]$.

So that, from Eq.(7) we have $D_{T}^{\omega}(A, B) \in[0,1]$ for all $A, B \in P F S(U)$.

(PF-Diss 1). It is obviously.
(PF-Diss 2). It is obviously.

(PF-Diss 3). If $A \subset B \subset C$ then

$$
\left\{\begin{array}{l}
\mu_{A}\left(u_{i}\right) \leq \mu_{B}\left(u_{i}\right) \leq \mu_{C}\left(u_{i}\right) \\
\eta_{A}\left(u_{i}\right) \leq \eta_{B}\left(u_{i}\right) \leq \eta_{C}\left(u_{i}\right) \\
\gamma_{A}\left(u_{i}\right) \geq \gamma_{B}\left(u_{i}\right) \geq \gamma_{C}\left(u_{i}\right)
\end{array}\right.
$$

for all $u_{i} \in U$.

So that $T_{A}\left(u_{i}\right) \leq T_{B}\left(u_{i}\right) \leq T_{C}\left(u_{i}\right)$

and

$$
S_{A}\left(u_{i}\right) \leq S_{B}\left(u_{i}\right) \leq S_{C}\left(u_{i}\right)
$$

Hence

$$
\left|T_{A}\left(u_{i}\right)-T_{C}\left(u_{i}\right)\right| \geq \max \left\{\left|T_{A}\left(u_{i}\right)-T_{B}\left(u_{i}\right)\right|,\left|T_{B}\left(u_{i}\right)-T_{C}\left(u_{i}\right)\right|\right\}
$$
and

$$
\left|S_{A}\left(u_{i}\right)-S_{C}\left(u_{i}\right)\right| \geq \max \left\{\left|S_{A}\left(u_{i}\right)-S_{B}\left(u_{i}\right)\right|,\left|S_{B}\left(u_{i}\right)-S_{C}\left(u_{i}\right)\right|\right\}
$$

Hence $D M_{T}^{\omega}(A, C) \geq \max \left\{D M_{T}^{\omega}(A, B), D M_{T}^{\omega}(B, C)\right\}$.

It means PF-Diss 3 satisfy.

\section{b) We have}

From eq.(1), eq.(2), eq.(3) and eq.(4), we have $-1 \leq T_{A}\left(u_{i}\right), T_{B}\left(u_{i}\right), S_{A}\left(u_{i}\right), S_{B}\left(u_{i}\right) \leq 1$ for all $i=1,2, \ldots, n$.

Hence, according to Eq.(5) we have $D_{i}(A, B) \in[0,1]$.

So that, from Eq.(7) we have $\operatorname{DM}_{P}^{\omega}(A, B) \in[0,1]$ for all $A, B \in P F S(U)$.

(PF-Diss 1). It is obviously.

(PF-Diss 2). It is obviously.

(PF-Diss 3). If $A \subset B \subset C$ then

$$
\left\{\begin{array}{l}
\mu_{A}\left(u_{i}\right) \leq \mu_{B}\left(u_{i}\right) \leq \mu_{C}\left(u_{i}\right) \\
\eta_{A}\left(u_{i}\right) \leq \eta_{B}\left(u_{i}\right) \leq \eta_{C}\left(u_{i}\right) \\
\gamma_{A}\left(u_{i}\right) \geq \gamma_{B}\left(u_{i}\right) \geq \gamma_{C}\left(u_{i}\right)
\end{array}\right.
$$

for all $u_{i} \in U$.

So that

$$
\begin{aligned}
& T_{A}\left(u_{i}\right) \leq T_{B}\left(u_{i}\right) \leq T_{C}\left(u_{i}\right) \\
& \text { and } \\
& S_{A}\left(u_{i}\right) \leq S_{B}\left(u_{i}\right) \leq S_{C}\left(u_{i}\right) \\
& \text { Hence } \\
& \left|T_{A}\left(u_{i}\right)-T_{C}\left(u_{i}\right)\right| \geq \max \left\{\left|T_{A}\left(u_{i}\right)-T_{B}\left(u_{i}\right)\right|,\left|T_{B}\left(u_{i}\right)-T_{C}\left(u_{i}\right)\right|\right\}
\end{aligned}
$$
and

$$
\left|S_{A}\left(u_{i}\right)-S_{C}\left(u_{i}\right)\right| \geq \max \left\{\left|S_{A}\left(u_{i}\right)-S_{B}\left(u_{i}\right)\right|,\left|S_{B}\left(u_{i}\right)-S_{C}\left(u_{i}\right)\right|\right\}
$$

Hence $D M_{P}^{\omega}(A, C) \geq \max \left\{D M_{P}^{\omega}(A, B), D M_{P}^{\omega}(B, C)\right\}$.

It means PF-Diss 3 satisfy. $\square$ 


\section{ThE PRoposed MCDM METHOD}

In this section, we propose a new method for the multicriteria decision making problems which based on the dissimilarity of picture fuzzy sets. The multi-criteria decision making problem is determined the best alternative from the concepts of the compromise solution. The best compromise solution is the alternative which obtains the farthest dissimilarity measure from each alternative to the perfect choice. The procedures of the proposed method can be expressed as follows. Let $A=\left\{A_{1}, A_{2}, \ldots, A_{m}\right\}$ be the set of alternatives. Let $C=\left\{C_{1}, C_{2}, \ldots, C_{n}\right\}$ be the set of criteria with the weights of each criteria $C_{j}$ is $\omega_{j}$ where $j=1,2, \ldots, n$ and $\sum_{j=1}^{n} \omega_{j}=1$. The picture fuzzy decision making matrix $D=\left[d_{i j}\right] \quad$ in which $d_{i j}=\left(d_{i j}^{1}, d_{i j}^{2}, d_{i j}^{3}\right)$ $\in \operatorname{PFS}\left(C_{j}\right)$, where $j=1,2, \ldots, n$ and $i=1,2, \ldots, m$ as follow

$$
\begin{gathered}
C_{1} \\
A_{1} \\
A_{2} \\
\ldots \\
A_{m}
\end{gathered}\left[\begin{array}{cccc}
d_{11} & d_{12} & \ldots & C_{n} \\
d_{21} & d_{22} & \ldots & d_{1 n} \\
\ldots & \ldots & \ldots & \ldots \\
d_{m 1} & d_{m 2} & \ldots & d_{m n}
\end{array}\right]
$$

The proposed method is presented with these following steps.

\section{Step 1. Normalization the decision matrix}

In this step, we construct the picture fuzzy decision making matrix. For instance, for all $j=1,2, \ldots, n$ and $i=1,2, \ldots, m$, we calculate

$$
\begin{gathered}
C_{j} \\
A_{1} \\
A_{2} \\
\cdots \\
A_{m}
\end{gathered}\left[\begin{array}{ccc}
c_{1 j}^{1} & c_{1 j}^{2} & c_{1 j}^{3} \\
c_{2 j}^{1} & c_{2 j}^{2} & c_{2 j}^{3} \\
\cdots & & \\
c_{m j}^{1} & c_{m j}^{2} & c_{m j}^{3}
\end{array}\right]
$$

$$
\begin{aligned}
& C_{j}
\end{aligned}
$$

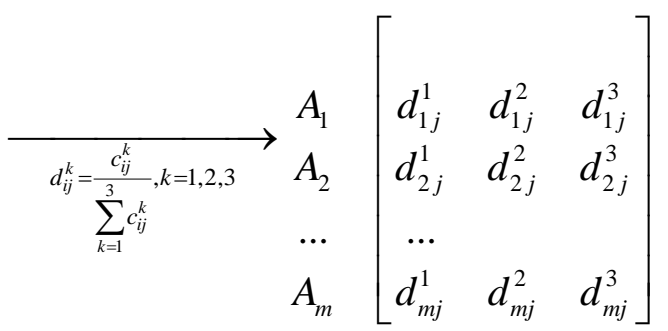

Then decision making matrix $D=\left[d_{i j}\right]$, in which $d_{i j}=\left(d_{i j}^{1}, d_{i j}^{2}, d_{i j}^{3}\right) \in \operatorname{PFS}\left(C_{j}\right)$, is a picture fuzzy decision making matrix, where $j=1,2, \ldots, n$ and $i=1,2, \ldots, m$. It means that $A_{i}$ is a picture fuzzy set on the criteria set $C=\left\{C_{1}, C_{2}, \ldots, C_{n}\right\}$.

This step is ignored if matrix $D$ is the given picture fuzzy decision making matrix.

\section{Step 2. Determine the weight of each criteria}

We determine the weight $\omega_{j}(j=1,2, \ldots, n)$ of the criteria $C_{j}(j=1,2, \ldots, n)$ such that

$$
\sum_{j=1}^{n} \omega_{j}=1
$$

\section{Step 3. Determine the perfect choice}

In this section, we determine the perfect choice. Here, we pay attention to the benefit criteria and cost criteria. Usually, with the perfect choices we can take the picture fuzzy number $(1,0,0)$ for the benefit criteria and $(0,0,1)$ for the cost criteria. Note that $(1,0,0)$ is the largest value of a picture fuzzy linguistic and $(0,0,1)$ is the smallest value of a picture fuzzy linguistic. So that the perfect choice $A_{b}$ get the picture fuzzy number $A_{b}(j)$ at the criteria $C_{j}$, in which $A_{b}(j)=(1,0,0)$ if $C_{j}$ is the benefit criteria and $A_{b}(j)=(0,0,1)$ if $C_{j}$ is the cost criteria, for all $j=1,2, \ldots, n$.

\section{Step 4. Calculate the dissimilarity measure of the each alternative to the perfect choice}

The dissimilarity measure of the each alternative and the perfect choice $\operatorname{Dis}\left(A_{i}, A_{b}\right)$. 


\section{Step 5. Ranking the alternatives}

Now, we can rank the alternatives based on the dissimilarity measure of the each alternative and the perfect choice as follows

$$
A_{i} \prec A_{k} \text { iff } \operatorname{Dis}\left(A_{i}, A_{b}\right) \leq \operatorname{Dis}\left(A_{k}, A_{b}\right)
$$

\section{Our Proposed Method For Evaluating Water REUSE APPLICATIONS}

In this section, we use our method proposed in section 3 for evaluating water reuse application. Data is taken from reference Pan et al [15]. This data is summarized as follows (Table 1, Table 2):

- Framework: The proposed has been applied to the City of Penticton (CoP), British Columbia (BC), Canada. The municipal water is used for residential, commercial, institutional and industrial sectors. The wastewater generated is collected and treated by the an advanced wastewater treatment plant by using biological nutrient removed technology. The treated water is partially reused and the remaining is discharged to a lake.

- $\quad$ Specific criteria: $C_{1}$ : public acceptability (PA); $C_{2}$ : freshwater saving (FS); $C_{3}$ : life cycle cost (LCC); $C_{4}$ : human health risk (HHR); and $C_{5}$ : the local governments' polices (GP).

We consider that $C_{1}, C_{2}, C_{5}$ are the benefit criteria and $C_{3}, C_{4}$ are the cost criteria.

- $\quad$ Alternative water reuses: $A_{1}$ : toilet flushing (TF); $A_{2}$ : vegetable watering in gardens (VW); $A_{3}$ : flower watering in gardens $(\mathrm{FW}) ; A_{4}$ : Agricultural irrigation $(\mathrm{AI}) ; A_{5}:$ Public parks watering $(\mathrm{PPW}) ; A_{6}$ :
Golf course watering $(\mathrm{GCW})$; and $A_{7}$ : drinking water (DW).

Now, we present the process of our method for this evaluating water reuse applications.

\section{Step 1. Normalization the decision matrix.}

From the Eq.(10), we obtain the normalization decision matrix (Table 3).

\section{Step 2. Determine the weight of criteria}

The weight of criteria $C_{j}$ is $\omega_{j}=0.2$ for all $j=1,2, \ldots, 5$.

\section{Step 3. Determine the perfect choice}

The perfect choice is

$$
A_{b}=\left(A_{b}(1), A_{b}(2), A_{b}(3), A_{b}(4), A_{b}(5)\right)
$$

where

$$
A_{b}(1)=A_{b}(2)=A_{b}(5)=(1,0,0)
$$

and

$$
A_{b}(3)=A_{b}(4)=(0,0,1) .
$$

Step 4. Calculate the dissimilarity measure of the each alternative to the perfect choice

Using Eq.(9) with $p=1$, then dissimilarity measure of the each alternative and the perfect choice is calculated by Eq.(8). The results are shown in Table 4.

\section{Step 5. Ranking the alternatives}

We use Eq.(11) to rank the alternatives based on the

\begin{tabular}{|c|c|c|c|c|c|c|}
\hline \multirow{2}{*}{ Alternatives } & \multicolumn{3}{|c|}{$C_{1}:$ Public acceptability } & \multicolumn{3}{|c|}{$C_{2}:$ Freshwater saving (ML/year) } \\
\hline & Agree & Neutrality & Disagree & Low & Mid & High \\
\hline TF & 80 & 9 & 11 & 428.8 & 536 & 643.2 \\
\hline VW & 63.5 & 13 & 23.5 & 2624.8 & 3281 & 3937.2 \\
\hline FW & 84.5 & 10 & 5.5 & 3192.5 & 3990.6 & 4788.8 \\
\hline $\mathrm{AI}$ & 74.5 & 10 & 15.5 & 3192.5 & 3990.6 & 4788.8 \\
\hline PPW & 85.5 & 8 & 6.5 & 886.3 & 1107.9 & 1329.5 \\
\hline GCW & 88.5 & 7 & 4.5 & 361.8 & 452.3 & 542.7 \\
\hline DW & 24 & 14 & 62 & 3192.5 & 3990.6 & 4788.8 \\
\hline
\end{tabular}
dissimilarity measure of the each alternative and the perfect choice (Table 4).

Table 1. Data of public acceptability and freshwater saving 
Table 2. Data of life cycle cost, human health risk and government's polices

\begin{tabular}{|c|c|c|c|c|c|c|c|}
\hline \multirow[t]{2}{*}{ Alternatives } & \multicolumn{3}{|c|}{$C_{3}$ : life cycle cost } & \multicolumn{3}{|c|}{$C_{4}$ : human health risk } & \multirow{2}{*}{$\begin{array}{c}C_{5} \text { : governments' } \\
\text { polices }\end{array}$} \\
\hline & Low & Mid & High & Low & Mid & High & \\
\hline $\mathrm{TF}\left(A_{1}\right)$ & 1555358 & 1944198 & 2333038 & $7.10 \mathrm{E}-12$ & 7.51E-12 & $8.30 \mathrm{E}-12$ & $\mathrm{M}(0.5,0.4,0.1)$ \\
\hline $\operatorname{VW}\left(A_{2}\right)$ & 1637219 & 2046524 & 2455829 & $1.83 \mathrm{E}-11$ & $1.89 \mathrm{E}-11$ & $2.03 \mathrm{E}-11$ & $\mathrm{~L}(0.2,0.5,0.3)$ \\
\hline $\mathrm{FW}\left(A_{3}\right)$ & 834019 & 1042524 & 1251028 & $1.78 \mathrm{E}-11$ & $1.84 \mathrm{E}-11$ & $1.99 \mathrm{E}-11$ & $\mathrm{H}(0.8,0.1,0.05)$ \\
\hline $\operatorname{AI}\left(A_{4}\right)$ & 146660 & 183326 & 219991 & $9.07 \mathrm{E}-12$ & $1.00 \mathrm{E}-11$ & $1.26 \mathrm{E}-11$ & $\mathrm{M}(0.5,0.4,0.1)$ \\
\hline $\operatorname{PPW}\left(A_{5}\right)$ & 635529 & 794411 & 953293 & $9.34 \mathrm{E}-12$ & $9.77 \mathrm{E}-12$ & $1.07 \mathrm{E}-11$ & $\mathrm{H}(0.8,0.1,0.05)$ \\
\hline $\operatorname{GCW}\left(A_{6}\right)$ & 78219 & 97774 & 117328 & $8.43 \mathrm{E}-12$ & $8.87 \mathrm{E}-12$ & $9.83 \mathrm{E}-12$ & $\mathrm{M}(0.5,0.4,0.1)$ \\
\hline $\operatorname{DW}\left(A_{7}\right)$ & 1197674 & 1497092 & 1796511 & $2.76 \mathrm{E}-08$ & 4.01E-08 & $1.00 \mathrm{E}-07$ & $\operatorname{VL}(0.1,0,0.9)$ \\
\hline
\end{tabular}

Table 3. Decision matrix

\begin{tabular}{|l|l|l|l|l|l|}
\hline & \multicolumn{1}{|c|}{$C_{1}$} & \multicolumn{1}{|c|}{$C_{2}$} & \multicolumn{1}{c|}{$C_{3}$} & \multicolumn{1}{c|}{$C_{4}$} & $C_{5}$ \\
\hline$A_{1}$ & $(0.8,0.09,0.11)$ & $(0.266667,0.333333,0.4)$ & $(0.266667,0.333333,0.4)$ & $(0.309908,0.327804,0.362287)$ & $(0.5,0.4,0.1)$ \\
\hline$A_{2}$ & $(0.635,0.13,0.235)$ & $(0.266667,0.333333,0.4)$ & $(0.266667,0.333333,0.4)$ & $(0.318261,0.328696,0.353043)$ & $(0.2,0.5,0.3)$ \\
\hline$A_{3}$ & $(0.845,0.1,0.055)$ & $(0.266666,0.333331,0.400003)$ & $(0.266667,0.333333,0.4)$ & $(0.317291,0.327986,0.354724)$ & $(0.8,0.1,0.05)$ \\
\hline$A_{4}$ & $(0.745,0.1,0.155)$ & $(0.266666,0.333331,0.400003)$ & $(0.266666,0.333334,0.4)$ & $(0.286391,0.315756,0.397853)$ & $(0.5,0.4,0.1)$ \\
\hline$A_{5}$ & $(0.855,0.08,0.065)$ & $(0.266661,0.333333,0.400006)$ & $(0.266667,0.333333,0.4)$ & $(0.313318,0.327742,0.35894)$ & $(0.8,0.1,0.05)$ \\
\hline$A_{6}$ & $(0.885,0.07,0.045)$ & $(0.266657,0.333358,0.399985)$ & $(0.266667,0.333333,0.399999)$ & $(0.310726,0.326944,0.36233)$ & $(0.5,0.4,0.1)$ \\
\hline$A_{7}$ & $(0.24,0.14,0.14)$ & $(0.266666,0.333331,0.400003)$ & $(0.266667,0.333333,0.4)$ & $(0.16458,0.239117,0.596303)$ & $(0.1,0,0.9)$ \\
\hline
\end{tabular}

Table 4. Ranking of alternatives with dissimilarity

\begin{tabular}{|c|c|c|}
\hline Alternatives & $D M_{1}\left(A_{i}, A_{b}\right)$ & Rank \\
\hline TF & 0.377652 & 4 \\
\hline VW & 0.451457 & 6 \\
\hline FW & 0.348657 & 1 \\
\hline AI & 0.380642 & 5 \\
\hline PPW & 0.348826 & 2 \\
\hline GCW & 0.363685 & 3 \\
\hline DW & 0.579784 & 7 \\
\hline
\end{tabular}

Now, we give some results when use our method with the difference weight vectors (using Eq.(9) with $p=2$. For instance, with $\omega_{1}$ we consider health-risk's weight more important than others; with $\omega_{2}$ we ignore the Government policy criteria; and with $\omega_{3}$ we dismiss the public acceptability criteria. These present in Table 5 . Finally, we also recall the results cited in Pan et al. 2018 in Table 6.

Table 5. Ranking of alternatives with dissimilarity and weights

\begin{tabular}{|c|c|c|c|c|c|c|}
\hline \multirow[t]{2}{*}{ Alternatives } & \multicolumn{2}{|c|}{$\omega_{1}=(0.1,0.2,0.2,0.4,0.1)$} & \multicolumn{2}{|c|}{$\omega_{2}=(0.25,0.25,0.25,0.25,0)$} & \multicolumn{2}{|c|}{$\omega_{2}=(0,0.25,0.25,0.25,0.25)$} \\
\hline & $D M_{2}\left(A_{i}, A_{b}\right)$ & Rank & $D M_{2}\left(A_{i}, A_{b}\right)$ & Rank & $D M_{2}\left(A_{i}, A_{b}\right)$ & Rank \\
\hline $\mathrm{TF}$ & 0.655163 & 5 & 0.604568 & 4 & 0.636108 & 4 \\
\hline VW & 0.71036 & 7 & 0.65549 & 6 & 0.716843 & 6 \\
\hline FW & 0.635177 & 2 & 0.589318 & 3 & 0.596128 & 2 \\
\hline AI & 0.643393 & 4 & 0.609762 & 5 & 0.624569 & 3 \\
\hline PPW & 0.633343 & 1 & 0.589102 & 2 & 0.594673 & 1 \\
\hline GCW & 0.645413 & 3 & 0.580045 & 1 & 0.636155 & 5 \\
\hline DW & 0.704258 & 6 & 0.713761 & 7 & 0.800051 & 7 \\
\hline
\end{tabular}


Table 6. Our method's result and the results cited in Pan et al.[15].

\begin{tabular}{|c|c|c|c|c|c|}
\hline Alt. & $\begin{array}{c}\text { Our method with } \\
\text { weight } \omega\end{array}$ & Pro-economy & Pro-social & Pro-environment & WRAE with a generalized parameter \\
\hline TF & 4 & 5 & 5 & 5 & 5 \\
\hline VW & 6 & 6 & 6 & 6 & 6 \\
\hline FW & 1 & 2 & 1 & 1 & 3 \\
\hline AI & 5 & 4 & 4 & 2 & 2 \\
\hline PPW & 2 & 1 & 2 & 4 & 3 \\
\hline GCW & 3 & 3 & 7 & 7 & 7 \\
\hline DW & 7 & 7 & 7 & & \\
\hline
\end{tabular}

\section{CONCLUSION}

In this paper, we define some new dissimilarity measures of picture fuzzy sets ((Eq.2), Eq.(3) and Eq.(4)). After that, we introduce the MCDM with use the dissimilarity measure of picture fuzzy sets. Finally, we apply the proposed method to evaluate the water reuse applications. We also cite the results were determined in [15] to compare with our method. If the weight vector changes, the results will be also changed. Observe that, our method is easier to understand than the method of Pan [15]. Theory of picture fuzzy set is suitable for datastructured problems such as the problem of water reuse as seen in this paper.

\section{REFERENCES}

[1] K.T. Atanassov (1986). Intuitionistic fuzzy sets. Fuzzy sets and Systems, 20(1): 87-96.

[2] P.W. Bhutia and R. Phipon (2012). Application of AHP and TOPSIS method for supplier selection problem. IOSR Journal of Engineering, 2(10): 43-50.

[3] F.E. Boran, S. Genç, M. Kurt and D. Akay (2009). A multi-criteria intuitionistic fuzzy group decision making for supplier selection with TOPSIS method. Expert Systems with Applications, 36(8): 11363-11368.

[4] B.C. Cuong and V. Kreinovich (2013). Picture Fuzzy Sets-a new concept for computational intelligence problems. In Information and Communication Technologies (WICT), 2013 Third World Congress on, pp. $1-6$.

[5] O. Jadidi, F. Firouzi and E. Bagliery (2010). TOPSIS method for supplier selection problem. World Academy of Science, Engineering and Technology, 47: 956-958.

[6] S. Kavita, P. Yadav and S. Kumar (2009). A multi-criteria interval-valued intuitionistic fuzzy group decision making for supplier selection with TOPSIS method. Lecture Notes in Computer Science, 5908: 303-312.

[7] L.H. Son (2015). DPFCM: A novel distributed picture fuzzy clustering method on picture fuzzy sets. Expert systems with applications, 42: 51-66.

[8] L.H. Son (2017). Measuring analogousness in picture fuzzy sets: from picture distance measures to picture association measures. Fuzzy Optimization and Decision Making, pp. 1-20.

[9] M.A. Maldonado, A. Alvarado, J.L. García and C.O. Balderrama (2014). Intuitionistic fuzzy TOPSIS for ergonomic compatibility evaluation of advanced manufacturing technology. The International Journal of Advanced Manufacturing Technology, 70(9-12): 22832292.

[10] G.W. Miller (2006). Integrated concepts in water reuse: managing global water needs. Desalination, 187: 65-75.

[11] N.D Hoa and P.H Thong (2017). Some Improvements of Fuzzy Clustering Algorithms Using Picture Fuzzy Sets and Applications for Geographic Data Clustering. VNU Journal of Science: Computer Science and Communication Engineering, 32(3): 32-38.

[12] N.V. Dinh, N.X. Thao and N.M. Chau (2015). On the picture fuzzy database: theories and application. J. Sci, 13(6): 1028-1035.

[13] N.V. Dinh, N.X. Thao and N.M. Chau (2017). Some dissimilarity measures of picture fuzzy set. FAIR'2017, pp. 104-109.

[14] D.E. Omorogbe (2016). A review of intuitionistic fuzzy topsis for supplier selection. AFRREV STECH: An International Journal of Science and Technology, 5(2): 91102.

[15] Q. Pan, Chhipi-Shrestha, D. Zhou, K. Zhang, K. Hewage and R. Sadiq (2018). Evaluating water reuse applications under uncertainty: generalized intuitionistic fuzzy-based approach. Stochastic Environmental Research and Risk Assessment, 32(4), 1099-1111.

[16] D.L. Pérez., A. Alvarado-Iniesta, I. Rodríguez-Borbón and O. Vergara-Villegas (2015). Intuitionistic fuzzy MOORA for supplier selection. Dyna, 82(191): 34-41.

[17] R. Solanki, G. Gulati, A. Tiwari and Q.M.D. Lohani (2016, July). A correlation based Intuitionistic fuzzy TOPSIS method on supplier selection problem. In Fuzzy Systems (FUZZ-IEEE), 2016 IEEE International Conference on, pp. 2106-2112.

[18] A.Y. Yayla, A. Yildiz and A. Özbek (2012). Fuzzy TOPSIS method in supplier selection and application in the garment industry. Fibres \& Textiles in Eastern Europe, 4(93): 20-23.

[19] A. Yildiz, and Yayla A.Y. (2015). Multi-criteria decisionmaking methods for supplier selection: A literature review. South African Journal of Industrial Engineering, 26(2): 158-177.

[20] L.A. Zadeh (1965). Fuzzy sets. Information and control, 8(3): 338-353.

[21] Zarghami M. and F. Szidarovszky (2009). Stochasticfuzzy multi criteria decision making for robust water resources management. Stoch Environ Res Risk Assess, 23:329-339.

[22] S. Zeng and Y. Xiao (2016). TOPSIS method for intuitionistic fuzzy multiple-criteria decision making and its application to investment selection. Kybernetes, 45(2): 282-296. 


\section{Author's Profile}

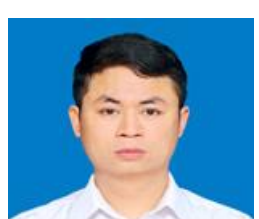

N.X. Thao was born on October 28, 1982 in Thai Binh, Viet Nam. He received the B.Sc. and M.S Degrees, in Mathematic from The College of Science Vietnamese National University (VNU), Hanoi, in 2004 and 2009, respectively. Now, he is a lecturer, Department of applied MathInformatics, Faculty of Information Technology, Vienam National University of Agriculture (VNUA), Viet Nam. He is teaching Calculus, Optimization, Fuzzy logic and its application. His research interests are Spectral theory of operator Fuzzy set theory, Rough set theory and application in data mining. Some articales on similarity topics he has published: Remarks on the spectrum of a compact convex set of compact operators, Journal of Applied Analysis 16 (2010), pp 259-264; Rough Fuzzy Relation on Two Universal Sets, I.J. Intelligent Systems and Applications, 2014, 04, 49-55; "Support-intuitionistic fuzzy set: a new concept for soft computing". International Journal of Intelligent Systems and Applications, ISSN: 2074-904X . MECS Press, Hong Kong. 2015, 04. p. 11 - 16; "Support-Neutrosophic Set: A New Concept in Soft Computing", International Journal in Neutrosophic Sets and Systems, New Mexico University Press, NM 87301, USA. ISSN 2331-6055. Vol. 16, 2017, p.93 - 98. "A new correlation coefficient of the intuitionistic fuzzy sets and its applications, Vol 35(2), 1959-1968.

How to cite this paper: Nguyen Xuan Thao," Evaluating Water Reuse Applications under Uncertainty: A Novel Picture Fuzzy Multi Criteria Decision Making Medthod", International Journal of Information Engineering and Electronic Business(IJIEEB), Vol.10, No.6, pp. 32-39, 2018. DOI: 10.5815/ijieeb.2018.06.04 